DOI 10.37882/2223-2974.2021.02.11

\title{
ПРЕДЕЛ СНИЖЕНИЯ СТАВОК ПО ИПОТЕКЕ В 2021 ГОДУ
}

\section{LIMIT ON MORTGAGE RATE CUTS IN 2021 \\ E. Metreveli}

Summary: The purpose of this article is to study the limit of reduction in mortgage rates by the end of 2021.

The object of the study is the cost of mortgage lending in the Russian Federation.

The subject of the study is the factors influencing the value of mortgage interest rates, as well as the forecast of their changes in 2021.

To conduct the study, the following methods were used:

- statistical analysis (calculation of the dynamics of changes in mortgage rates for 2008-2020);

- correlation analysis of the relationship between mortgage rates, the level of inflation, as well as the rate of growth in real estate prices.

The information base of the study was the data published by Rosstat (Federal state statistics service) and the Central Bank of Russia.

The article defines the characteristic features of mortgage lending and analyzes the dynamics of changes in interest rates on mortgage lending for 2008-2020, makes a forecast of changes in mortgage interest rates at the end of 2021. The components elements of interest credit rates that are cost risk, the cost of Bank's costs and profit margin.

According to the forecast using a regression model, the mortgage lending rate in 2021 may reach $7.55 \%$. The factors influencing the cost of mortgage lending are determined and it is concluded that the maximum impact on the final rate of housing mortgage lending is exerted by the factor of inflation.

Thus, the marginal decline in mortgage lending is near $7.5 \%$, which is higher than at the end of 2020. This correlates with expert forecasts and corresponds to the current socio-economic situation.

Keywords: mortgage, mortgage lending, interest rates, inflation, real estate price growth rates, credit, lending, key rate, real estate market, mortgage rates forecast.
Метревели Елизавета Георгиевна

преподаватель, аспирант, РЭУ им. Г.В. Плеханова metrevelieg@yandex.ru

Аннотация: Целью данной статьи является исследование предела снижения ставок по ипотеке к концу 2021 года.

0бъектом исследования является стоимость ипотечного кредитования в Российской Федерации.

Предметом исследования являются факторы, оказывающие влияние на величину процентных ипотечных ставок, а также прогноз их изменения в 2021 году.

Для проведения исследования была использованы следующие методы:

- статистический анализ (расчет динамики изменения ставок по ипотеке за 2008-2020 гг.);

- корреляционный анализ взаимосвязи между ставками по ипотеке, уровнем инфляции, а также темпом роста цен на недвижимость.

Информационной базой исследования выступили данные, опубликованные Росстатом (Федеральной службой государственной статистики) и ЦБ России. В статье определены характерные особенности ипотечного кредитования и проведен анализ динамики изменения процентных ставок по ипотечному кредитованию за 2008-2020 гг., сделан прогноз изменения ипотечных процентных ставок на конец 2021 года. Рассмотрены составляющие элементы процентной кредитной ставки, которыми выступают стоимость риска, стоимость расходов банка, а также маржа прибыли.

Согласно прогнозированию с использованием регрессионной модели, ставка по ипотечному кредитованию в 2021 году может составить 7,55\%. Определены факторы, оказывающие влияние на стоимость ипотечного кредитования и сделан вывод, что максимальное воздействие на итоговую ставку ипотечного жилищного кредитования оказывает фактор инфляции.

Таким образом, предельное снижение ипотечного кредитования находится вблизи 7,5\%, что выше, чем в конце 2020 г. Это коррелирует с экспертными прогнозами и соответствует текущей социально-экономической ситуации.

Ключевые слова: ипотека, ипотечное кредитование, процентные ставки, инфляция, темпы роста цен на недвижимость, кредит, кредитование, ключевая ставка, рынок недвижимости, прогноз ставок по ипотеке.

на, И.М. Осколкова, Д.С. Трофимова, Р.Р. Ситникова [8], В.С. Сошниковой [12], Л.Ю. Новицкой, М.В. Кошелевой [10], Е.В. Добролежа, С.В. Соколова [4], Г.В. Морозовой, Ю.Ю. Филичкиной [9] и др. представлены особенности ипотечного кредитования в России. Проведен анализ и дана оценка рынка жилищного кредитования за последние годы в условиях нестабильности национальной экономики. Определен ряд наиболее актуальных проблем, не дающих ипотечному кредитованию активно развиваться в нынешних условиях. Исследованию факторов, оказывающих влияние на рост ипотечного рынка, а также на процентные ставки по ипотечному кредитованию, посвящены труды С.А. Сироткина [11], Е.А. Баркова, Т.В, Кузаева [2], С.С. Березин, А.В. Сибякина [3] и др.

В статьях А.В., Зверева, В.В. Мандрона, М.Ю. Мишиной [6], И.А. Долматович, Н.В. Кешенковой [5], А.С. Коки- 


\section{Шелесообразность разработки темы}

Несмотря на обширный анализ состояния ипотечного кредитования, в литературе не приводится прогноз по его развитию, в том числе, по потенциалу снижения ставок по ипотеке. Это также подтверждает актуальность выбранной темы.

\section{Шель и задачи исслеАования}

Целью данной статьи является исследование предела снижения ставок по ипотеке к концу 2021 года.

Для проведения исследования была использованы следующие методы:

- статистический анализ (расчет динамики изменения ставок по ипотеке за 2017-2020 гг.);

- корреляционный анализ взаимосвязи между ставками по ипотеке, ключевой ставкой, уровнем инфляции, а также рентабельностью активов;

- множественный регрессионный анализ между ставками по ипотеке, ключевой ставкой, уровнем инфляции, а также рентабельностью активов.

Теоретическая значимость работы заключается в разработке методических основ анализа и прогнозирования стоимости ипотечного кредитования, а также в исследовании факторов, которые оказывают влияние на стоимость ипотечного кредита.

Практическая значимость работы заключается в использовании теоретических и практических выводов данной статьи в деятельности органов государственной власти и управления, банковских учреждений, страховых компаний, негосударственных пенсионных фондов и в учебном процессе высших учебных заведений.

\section{Методология исследования}

Для проведения исследования была использованы следующие методы:

- статистический анализ (расчет динамики изменения ставок по ипотеке за 2008-2020 гг.);

- корреляционный анализ взаимосвязи между ставками по ипотеке, уровнем инфляции, а также темпом роста цен на недвижимость.

Для оценки взаимосвязи был рассчитан коэффициент корреляции по следующей формуле [7,c .8]:

$$
r_{x y}=\frac{\sum_{i=1}^{n}\left(x_{i}-\bar{x}\right)\left(y_{i}-\bar{y}\right)}{n \cdot \sigma_{x} \sigma_{y}},
$$

где $\mathrm{n}$ - объем выборки (анализируемой совокупности); $\bar{x}, \bar{y}$ - средние значения;

$\sigma_{x}^{2}, \sigma_{y}^{2}-$ дисперсии;

$\sigma_{x^{\prime}} \sigma_{y}$ - стандартные (среднеквадратические) отклонения признаков у и х.

Информационной базой исследования выступили данные, опубликованные Росстатом (Федеральной службой государственной статистики) и ЦБ России [21].

\section{Результаты исследования.}

Ипотека - одна из форм залога, когда недвижимость остается в собственности должника, но кредитор (банк) при неисполнении должником своего обязательства приобретает право продать это недвижимое имущество.

Ипотека имеет ряд характерных особенностей, отличающих ее от других форм кредитования:

1. Процентная ставка ниже.

2. Ипотечный дается на длительный период (5-50 лет).

3. Для оформления ипотечного кредита требуется достаточно большой пакет документов.

4. Существуют строгие требования к клиенту.

Размер процентной ставки на ипотеку зависит от множества факторов. К таким факторам стоит отнести: сумму первоначального взноса, срок использования кредита, вид жилья, уровень дохода ипотекополучателя. Ипотечный кредит является своеобразным товаром, цена которого состоит из прибыли и себестоимости. Себестоимость ипотечного кредита включает регуляторные издержки банка; операционные расходы; стоимость риска и заимствований. Для выдачи ипотечного кредитования коммерческий банк занимает деньги у вкладчиков (государства, организаций, граждан), ЦБ России, иностранных и российских финансовых структур. В настоящее время стоимость заимствований находится в диапазоне 4,25-6,25 процентов годовых. Стоимость риска, в свою очередь, находится в прямой зависимости от ситуации в стране, от обеспечения по кредиту, от типа заемщика и вида кредита. Стоимость риска для ипотеки оценивается на уровне 0,6-1\% [19]. Издержки и расходы банков, по мнению экспертов, составляют около 2,2-2,5\%. При этом прибыль банков находится на уровне 0,5\%.

Таким образом, ставка по ипотеке в настоящее время в коммерческих банках варьируется от 7,55-10,25\% годовых.

Динамика средневзвешенной ставки по ипотечному жилищному кредитованию в РФ в 2008-2020 гг. представлена на рис. 1.

Из рис. 1 видно, что если в 2008 г. средневзвешенная ставка по ипотечному жилищному кредитованию со- 
ставляла 12,9\%, то к октябрю 2020 г. она снизилась на 5,59 процентных пунктов, до 7,31\% годовых [21].

Средняя ипотечная ставка снижалась вслед за динамикой снижения ключевой ставки Центрального банка. С начала кризиса весны 2020 года, вызванного пандемией коронавируса и обвалом цен на нефть, Банк России снизил ключевую ставку на 1,75 п.п. - с 6 до 4,25\%. В сентябре и октябре 2020 года Банк России держит паузу в смягчении своей политики, что выражается в сохранении уровня ключевой ставки [18].

За 2020 год наблюдалось снижение процентных ставок на рынке ипотечного кредитования - с 9,66\% до рекордного значения 7,31\%. Для первичной жилой недвижимости ставки опустились до 6,5\% за счет действия программы льготной ипотеки от государства [18].

В 2021 г. средняя ипотечная ставка может достичь 6,8-7\%. Эксперты считают, что пузырь на рынке недвижимости в 2021 году вряд ли сформируется [14]. То есть ставки ипотечных кредитов не будут кардинально ни увеличиваться, ни снижаться. Однако к Новому 2021 году от банков страны можно ожидать аукционные предложения по оформлению кредитов со сниженными ставками. Процентная ставка 6,7\% существенно стимулирует продажи недвижимости. При снижении есть вероятность увеличения спроса и тогда цены на квартиры вырастут еще. Динамика изменения цен на рынке недвижимости в 2019-2020 гг. представлена на рис. 2.

При низких процентных ставках государство ком-

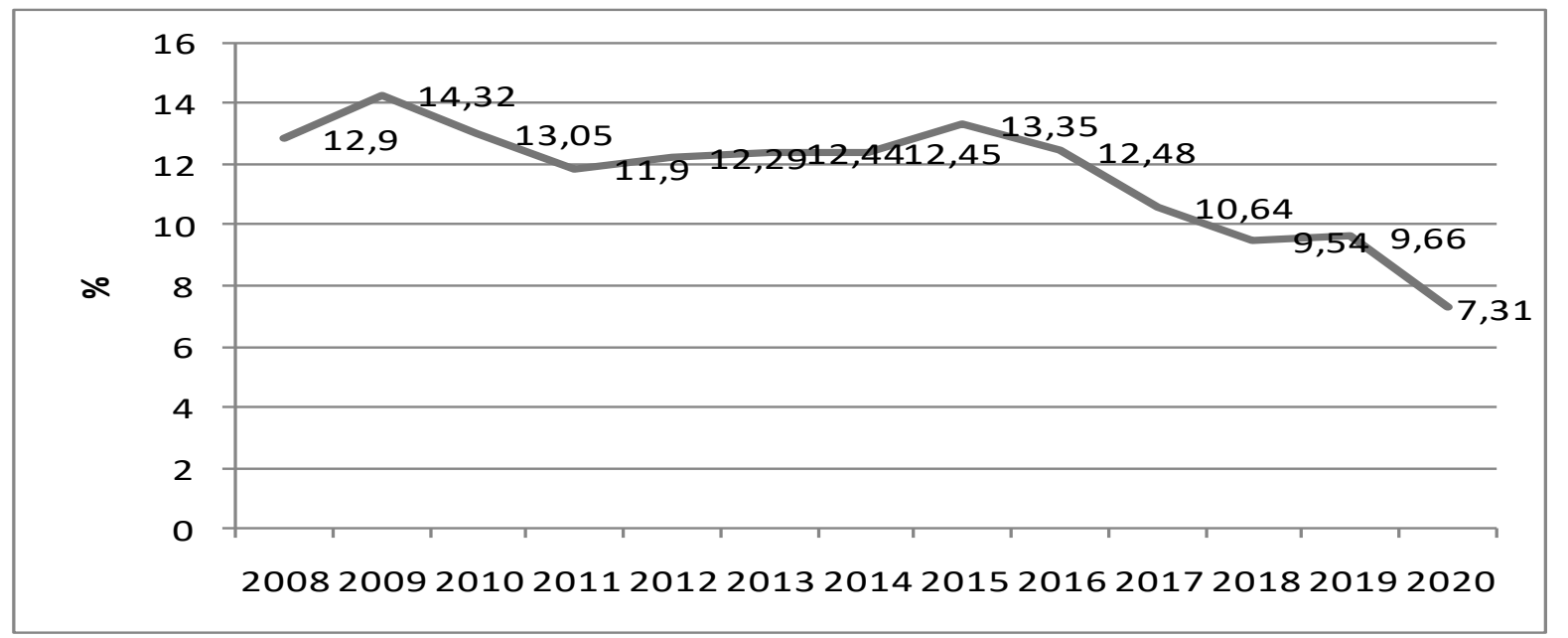

Рис. 1. Динамика средневзвешенной ставки по ипотечному жилищному кредитованию в РФ в 2008-2020 гг. Источник: [21]

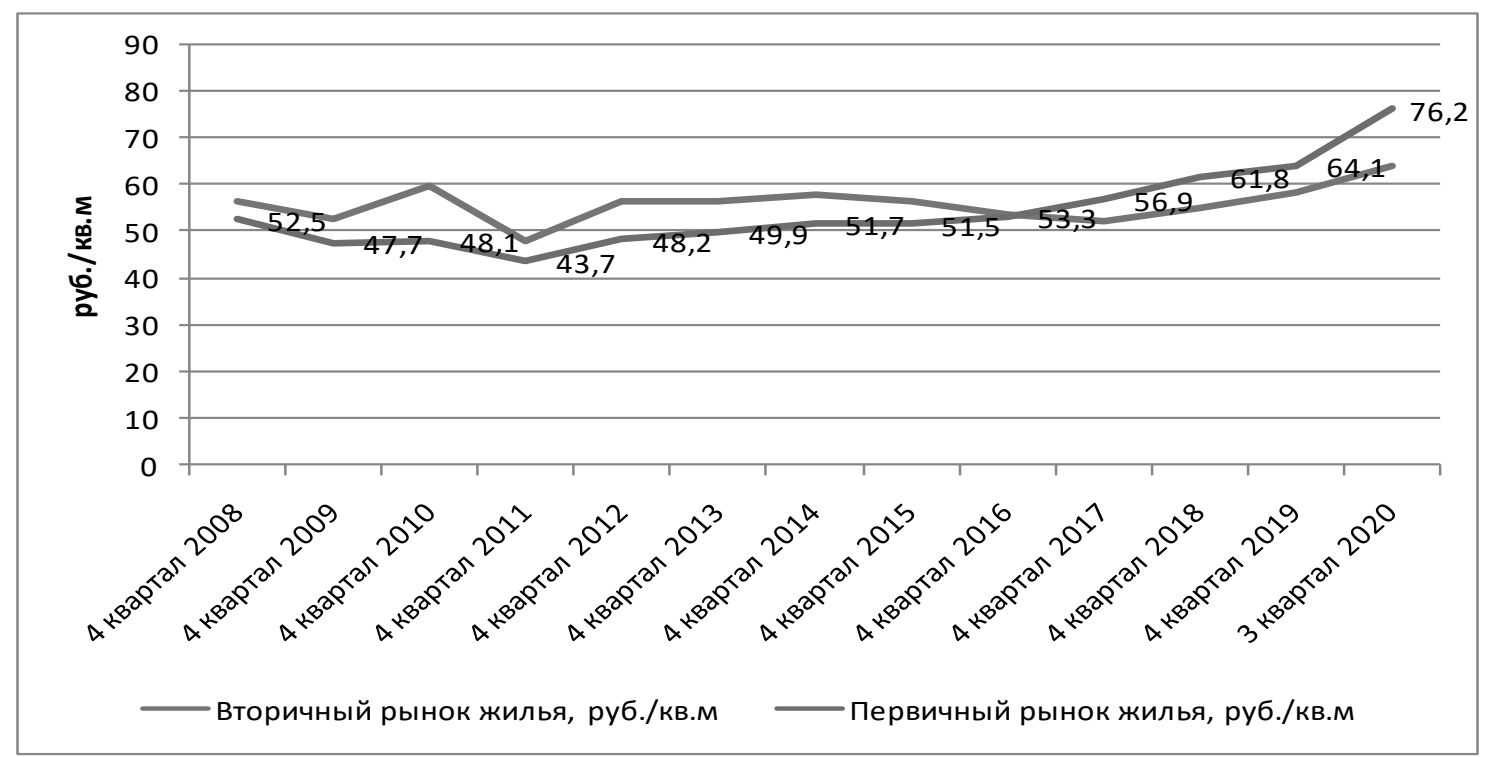

Рис. 2. Динамика изменения цен на рынке недвижимости в 2008-2020 гг. Источник: [15] 
пенсирует банкам прибыль, которую они недополучили в сравнении с рыночной ставкой. Это значит, что независимо от того, как будут развиваться события, банки останутся при выгодном проценте и получат доплату из бюджета государства [17].

Снижение спроса на льготные программы по ипотеке может быть связано со сближением ставок по государственной программе и программам конкретных банков. При дальнейшем стабильном росте цен на первичную недвижимость интерес заемщиков к вторичному рынку будет увеличиваться. В 2021 г. цена за 1 кв. м. будет расти медленнее (не превышая уровня роста инфляции).

Субсидирование государством ставки по ипотечному кредитованию в рамках программы государственной поддержки может повлечь резкое снижение спроса после завершения программы, и как следствие, к обрушению цен на недвижимость и росту рисков ипотечного кредитования для банков в связи с обесценением залогового имущества [16].

Высокий темп инфляции и дефицит у банков ста- бильных источников финансирования на долгосрочный период - ключевые факторы, не дающие рынку долгосрочного кредитования развиваться более быстрыми темпами. Согласно официальной статистике, в 2019 г. инфляция хоть и была на низком уровне (2019 год 3,04\%, 2018 - 4,26\%), 2017 - 2,51\%) [20], но все-таки ключевая ставка оставалась достаточно высокой - 6,25\% на 31.12.2019 г., 7,75\% на 31.12.2018 г. и 31.12.2017, хотя и снижалась в течение последних лет (в настоящее время ключевая ставка составляет 4,25\% [21]). По сравнению, аналогичная ставка в странах ЕС находится на уровне 1,25\%, в Соединенных Штатах - 0,25\%. Соответственно, стоимость денег в этих странах ниже, а ипотечные кредиты выдаются под 3-6\%.

Исходные данные для проведения корреляционного анализа зависимости процентной ставки по ипотечному жилищному кредитованию представлены в табл. 1. Как можно видеть из таблицы 1, при изменении ставок инфляции с 13,3\% до 3,3\% и темпа роста цен на рынке первичной жилой недвижимости с 17,8\% до 18,88\% ставки по ипотечному жилищному кредитованию снижалась с $12,9 \%$ до $7,31 \%$.

Таблица 1.

Исходные данные для проведения корреляционного анализа зависимости процентной ставки по ипотечному жилищному кредитованию

\begin{tabular}{|c|c|c|c|}
\hline Годы & $\begin{array}{c}\text { Ставка по ипотечному жилищному } \\
\text { кредитованию, \% (Y) }\end{array}$ & Инфляция, \% (x1) & $\begin{array}{c}\text { Темп роста цен на первичном рынке } \\
\text { жилья, \%(х2) }\end{array}$ \\
\hline 2008 & 12,9 & 13,3 & 17,8 \\
\hline 2009 & 14,32 & 8,8 & $-9,14$ \\
\hline 2010 & 13,05 & 8,8 & 0,84 \\
\hline 2011 & 11,9 & 6,1 & $-9,15$ \\
\hline 2012 & 12,29 & 6,6 & 10,30 \\
\hline 2013 & 12,44 & 6,5 & 3,53 \\
\hline 2014 & 12,45 & 11,4 & 3,61 \\
\hline 2015 & 13,35 & 12,9 & $-0,39$ \\
\hline 2016 & 12,48 & 5,4 & 3,50 \\
\hline 2017 & 10,64 & 2,5 & 6,75 \\
\hline 2018 & 9,54 & 4,3 & 8,61 \\
\hline 2019 & 9,66 & 3 & 3,72 \\
\hline 2020 & 7,31 & 3,3 & 18,88 \\
\hline
\end{tabular}

Источник: составлено автором на основе: [20], [21]

Таблица 2.

Матрица парных коэффициентов корреляции R

\begin{tabular}{|c|c|c|c|}
\hline- & $y$ & $x_{1}$ & $x_{2}$ \\
\hline$y$ & 1 & 0.7193 & -0.5518 \\
\hline$x_{1}$ & 0.7193 & 1 & -0.1064 \\
\hline$x_{2}$ & -0.5518 & -0.1064 & 1 \\
\hline
\end{tabular}


В таблице 2 продемонстрирована матрица парных коэффициентов корреляции $\mathrm{R}$.

Берем из матрицы парных коэффициентов корреляции:

$$
\begin{aligned}
& 0,719=\beta_{1}-0,106 \beta_{2} \\
& -0,552=-0,106 \beta_{1}+\beta_{2}
\end{aligned}
$$

Для решения этой системы линейных уравнений воспользуемся методом Гаусса: $\beta_{1}=0,668 ; \beta_{2}=-0,481$;

По итогам проведенных расчетов получаем уравнение множественной регрессии, имеющее следующий вид:

$$
Y=9,7125+0,3499 \times 1-0,1094 X 2 .
$$

Параметры модели могут быть интерпретированы с экономической позиции. Так, при росте инфляции на один процент происходит увеличение ставки по ипотечному кредитованию в среднем на 0,35\%. При увеличении темпа роста цен на рынке первичной недвижимости на 1\% происходит уменьшение ставки по ипотечному кредитованию в среднем на 0,109\%. Исходя из максимального значения коэффициента $\beta_{1}=0,668$ приходим к выводу, что максимальное воздействие на итоговую ставку ипотечного жилищного кредитования оказывает фактор инфляции.

По данным ЦБ России, годовой уровень инфляции в стране в условиях реализуемой государственной кредитно-денежной политики будет составлять в 2021 г. около 3,5-4\%. В будущем значение показателя так и останется на уровне 4\% [1]. Относительно 2020 г. темп инфляции будет выше на 0,7\%. Следовательно, согласно регресси- онной модели, ставка по ипотечному кредитованию в 2021 году может составить: 0,7*0,35 + 7,31 = 7,55\%. Таким образом, предельное снижение ипотечного кредитования находится вблизи 7,5\%. С этим мнением согласны и эксперты. Отмечается, что ключевая ставка ЦБ России достигла своего минимального значения - 4,25\%. За всю историю она еще не опускалась ниже. В таких условиях ипотечная ставка может быть сохранена на относительно невысоком уровне. Даже если программы льготного ипотечного кредитования будут свернуты, ставка поднимется максимум до 7-8\% [16].

\section{Выводы}

Фактор роста уровня цен на недвижимость оказывает незначительное влияние на уровень ставки по ипотеке. По прогнозам экспертов, недвижимость будет расти в пределах уровня инфляции в 2021 году. Следовательно, предельное значение ставки ипотечного кредитования будет составлять 7,5\%.

\section{Зак^ючение}

Таким образом, на уровень ставки процента по ипотеке оказывает влияние, как уровень инфляции, так и уровень темпов роста цен на недвижимость на первичном рынке. При этом, как было установлено, влияние уровня инфляции на ставку по ипотечным жилищным кредитам более сильное, чем фактор роста цен на недвижимость. В связи с этим, опираясь на прогноз уровня инфляции в 2021 году, можно прогнозировать предел ставки ипотечного кредитования. Согласно регрессионной модели, ставка по ипотечному кредитованию в 2021 году может составить 7,55\%. Таким образом, предельное снижение ипотечного кредитования находится вблизи 7,5\%.

\section{ЛИТЕРАТУРА}

1. Основные направления единой государственной денежно-кредитной политики на 2021 год и период 2022 и 2023 годов [Электронный ресурс]. - Режим доступа: https://cbr.ru/about_br/publ/ondkp/on_2021_2023/(дата обращения 07.12.2020)

2. Баркова Е.А., Кузаева Т.В. Факторы ипотечного кредитования в современной экономике (обзор экономических концепций и эмпирических результатов) //Экономика и предпринимательство. - 2020. - № 4 (117). - С. 1157-1159.

3. Березин С.С., Сибякина А.В. Взаимосвязь цен на недвижимость и отдельных индикаторов кредитного рынка в современных условиях в Российской Федерации//Вестник Российского экономического университета им. Г.В. Плеханова. Вступление. Путь в науку. - 2017. - № 3 (19). - С. 113-121.

4. Добролежа Е.В., Соколов С.В. Что же мешает развиваться отечественному ипотечному жилищному кредитованию в современных условиях? //Инновационные технологии в машиностроении, образовании и экономике. - 2018. - Т. 14. - № 1-2 (7). - С. 125-128.

5. Долматович И.А., Кешенкова Н.В. Ипотечное жилищное кредитование в России: проблемы и решения//Деньги и кредит. - 2017. - № 3. - С. 33-37.

6. Зверев А.В., Мандрон В.В., Мишина М.Ю. Состояние рынка ипотечного кредитования в России на современном этапе//Вопросы региональной экономики. -2018. - № 3 (36). - С. 117-124.

7. Ишханян, М.В., Карпенко, Н.В. Эконометрика: учебное пособие / М.В. Ишханян, Н.В. Карпенко. Часть 1.Парная регрессия. - М.: МГУПС (МИИТ), 2016. 117 c.

8. Кокин А.С., Осколков И.М., Трофимова Д.С., Ситников Р.Р. Анализ современного состояния рынка ипотечного жилищного кредитования в России//Экономика: вчера, сегодня, завтра. - 2018. - Т. 8. - № 5А. - С. 127-142.

9. Морозова Г.В., Филичкина Ю.Ю. Вопросы развития рынка ипотечного кредитования в современных условиях//Финансовая экономика. - 2018. - № 4. C. 222-227. 
10. Новицкая Л.Ю., Кошелева М.В. Некоторые проблемы, связанные с ипотечным кредитованием в Российской Федерации//Экономика. Право. Общество. 2017. - № 3 (11). - C. 57-63.

11. Сироткин С.А. Рынок ипотечного кредитования в России: динамика и факторы, влияющие на его развитие//В сборнике: экономика и управление: теория и практика. - 2018. - С. 254-260.

12. Сошникова В.С. Проблемы и перспективы развития современного рынка ипотечного кредитования в России и регионе//Молодой ученый. - 2017. - № 21-1 (155). - - . 88-92.

13. Хейгетян С.Х., Иванченко И. С. оценка современного состояния ипотечного кредитования в России//В сборнике: Новая наука: современное состояние и пути развития Материалы Международной (заочной) научно-практической конференции. Под общей редакцией А.И. Вострецова. - 2019. - С. 76-83.

14. Аналитики назвали предел снижения ставок по ипотеке в 2021 году [Электронный ресурc]. - Режим доступа: https://www.rbc.ru/finances/30/11/2020/5fc 170с29a79477е333183е5 (дата обращения 07.12.2020)

15. ЕМИСС [Электронный ресурс]. - Режим доступа: https://www.fedstat.ru/indicator/31452 (дата обращения 07.12.2020)

16. Захарченко А. Недвижимость-2021: России обещают ипотечный кризис по типу американского [Электронный ресурс].- Режим доступа: https://svpressa. ru/realty/article/279829/ (дата обращения 07.12.2020)

17. Ипотека в 2021 году: процентная ставка [Электронный ресурс]. - Режим доступа: https://2021god.com/ipoteka-v-2021-godu-procentnaya-stavka/ (дата обращения 07.12.2020)

18. Ипотека показала вирусный рост [Электронный ресурс]. - Режим доступа: https://www.rbc.ru/ (дата обращения 07.12.2020)

19. Какими могут быть ставки по ипотеке в ближайший год [Электронный ресурс]. - Режим доступа: https://yandex.ru/turbo/mlds.ru/s/articles/ipoteka/ stavki-po-ipoteke-2020-2021/ (дата обращения 07.12.2020)

20. Росстат [Электронный ресурс]. - Режим доступа: https://rosstat.gov.ru/ (дата обращения 07.12.2020)

21. Сайт Банка России [Электронный ресурс]. - Режим доступа: https://cbr.ru/Collection/Collection/File/8468/obs_189.pdf (дата 0бращения 20.08.2020)

22. Сайт Федеральной службы государственной статистики [Электронный ресурс]. - Режим доступа: https://rosstat.gov.ru/price (дата 0бращения 21.08.2020)

(с) Метревели Елизавета Георгиевна (metrevelieg@yandex.ru).

Журнал «Современная наука: актуальные проблемы теории и практики»

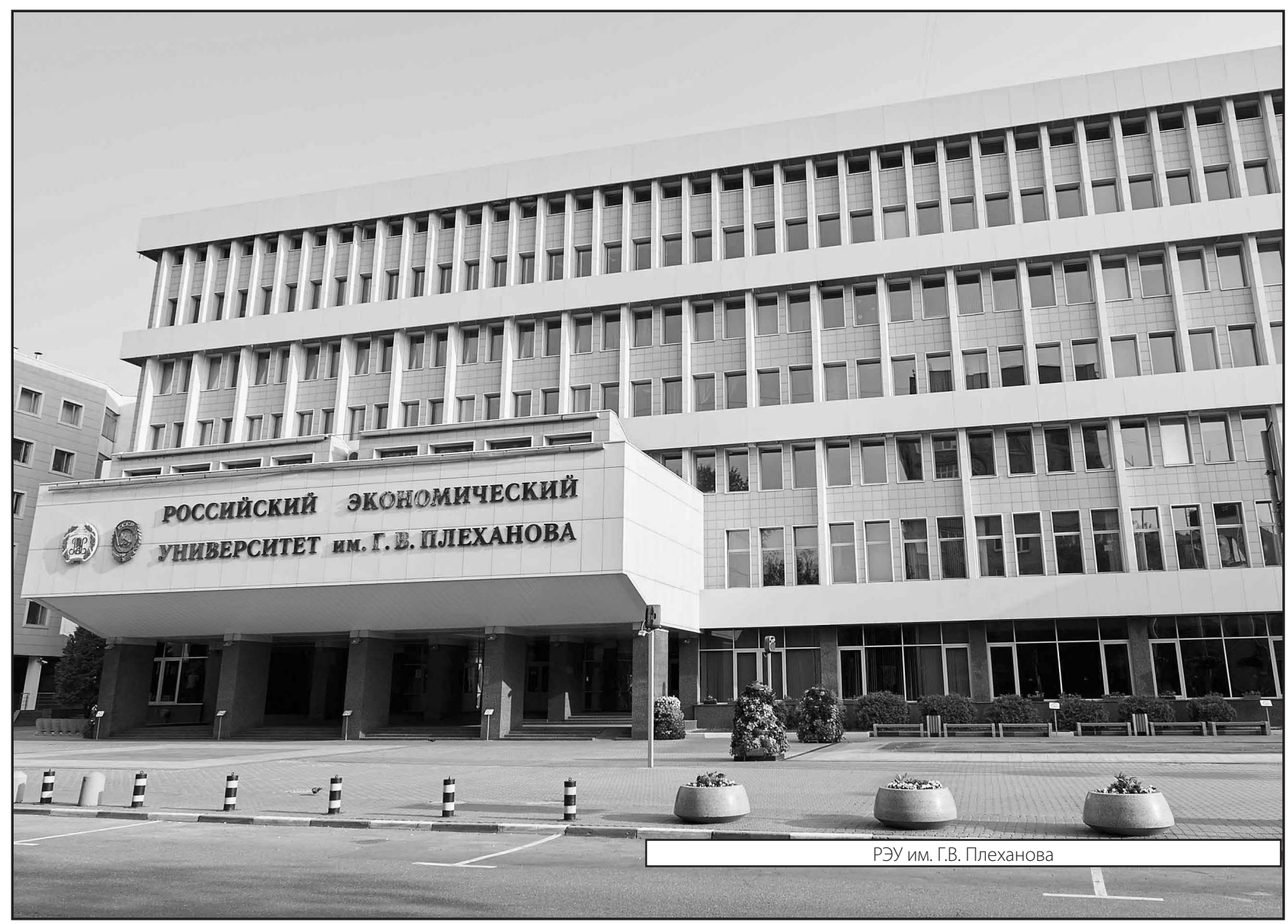

